\title{
Mechanisms of nutritional repletion during total parenteral nutrition
}

\author{
E PULLICINO AND M ELIA
}

Total parenteral nutrition (TPN) is a valuable form of treatment for patients with severe diffuse Crohns disease, or those with intestinal fistulae. In many cases TPN is used for nutrition rehabilitation as well as nutritional support. The mechanisms of intermediary metabolism during rehabilitation including the changes in fuel selection, energy expenditure, and mechanisms of nutrient deposition are poorly understood. Therefore the following study was undertaken to improve knowledge in this respect.

\section{Case history}

SS a 28 year old man with Crohn's disease of the small and large intestine presented in 1980 to his local hospital with diarrhoea, cramping abdominal pain, and weight loss. He was treated with salazopyrine and prednisolone until 1983 when he developed intestinal obstruction and came to laparotomy. Approximately $100 \mathrm{~cm}$ of mid small intestine were resected. This relieved the obstruction but the abdominal symptoms recurred. In 1986 the patient was referred to the Gastroenterology Department, Addenbrooke's Hospital for advice. Initially he did well on treatment with an elemental diet but 18 months later he was readmitted to Addenbrooke's with increasing abdominal pain, weight loss, and diarrhoea. He had a course of intravenous antibiotics during the week before his transfer from another hospital.

\section{EXAMINATION}

The patient was thin and weak (weight $52 \mathrm{~kg}$, height $191 \mathrm{~cm}$ ) with little subcutaneous fat and reduced muscle bulk. There were no external stigmata of Crohn's disease, and systemic examination was normal apart from the abdomen where there was ill defined mass rising out of the pelvis. Investigations showed: $\mathrm{Hb} 12.6 \mathrm{~g} / 100 \mathrm{ml}$, platelets $346 \times 10^{4} / \mathrm{l}$, white cell count $14.5 \times 10^{4} / 1$, albumin $25 \mathrm{~g} / \mathrm{l}$; ultra-sound of abdomen: multiple loops of matted bowel; barium follow through examination: at least five strictures in the small intestine and probable ileocolic fistula which was confirmed on enema examination.

MANAGEMENT

The patient was $35 \%$ below his ideal body weight and unable to eat a normal diet because of anorexia and abdominal pain. He was started on total parenteral nutrition (TPN) and he agreed to a detailed study of his nutritional progress. The TPN was given at night from $6 \mathrm{pm}$ to $9 \mathrm{pm}$ to give him maximum freedom during the day. The initial intravenous solution contained $300 \mathrm{~g}$ of Dextrose $(4 \cdot 7 \mathrm{MJ}), 12 \cdot 8 \mathrm{~g}$ nitrogen $(1.4 \mathrm{MJ})$, and $500 \mathrm{ml}$ of $20 \%$ Intralipid $(4 \cdot 2 \mathrm{MJ})$. Ninety five per cent of the total energy content of the feeding bag $(10 \cdot 3 \mathrm{MJ})$ was infused to give the patient $9 \cdot 8 \mathrm{MJ} /$ day. This was well tolerated and the carbohydrate intake was increased progressively to $1000 \mathrm{~g}$ giving a final energy intake of $20 \mathrm{MJ} /$ day. Progress was monitored by repeated measurements of body weight, skinfold thicknesses (measured at 4 standard sites), ' and bioelectrical impedance which provides a measure of lean body mass. ${ }^{2}$ Energy expenditure was assessed on 48 occasions using an automated indirect calorimeter attached to a ventilated hood. Measurements were made both during the 'on feed' and 'off feed' periods. Twenty four hour losses of nitrogen in urine and faeces were measured after each increment of energy intake.

Standard haematological and biochemical tests for a patient on TPN were carried out. ${ }^{3}$ The white cell count and the circulating acute phase protein concentrations (C-reactive protein and $\alpha_{1}$ antichymotrypsin) which were initially raised, returned to normal within a few days of commencing TPN.

\section{PROGRESS}

This patient's general condition improved markedly during the period of TPN. The inflammatory mass subsided and he was discharged home to continue intravenous feeding.

\section{Results}

During the seven week period of nutritional repletion, body weight increased linearly with time from 53 to $72 \mathrm{~kg}$. Estimates of skinfold thickness showed an increase in body fat from less than $5 \%$ body weight to approximately $15 \%$ body weight. Lean body mass, assessed by anthropometry also increased progressively from about 50.5 to $61 \mathrm{~kg}$. Sequential measurements of bioelectrical impedance confirmed 
an increase in total body water and lean body mass. It is estimated that $766 \mathrm{~g}$ nitrogen were infused of which approximately $280 \mathrm{~g}$ were retained.

The mean 'on feed' resting energy expenditure increased progressively from $4.35 \mathrm{~kJ} / \mathrm{min}$ to 7.20 $\mathrm{kJ} / \mathrm{min}$ and the corresponding resting 'on feed' respiratory quotient increased from 0.95 to 1.18 over the seven weeks. Towards the end of the study the respiratory quotient was repeatedly found to be greater than $1 \cdot 0$, even eight to nine hours after stopping the feed.

\section{Discussion}

This study shows the value of nocturnal intravenous feeding with high caloric fluids of a cachetic patient with diffuse gastrointestinal pathology. Accurate assessment of energy balance by comparing energy intake with measurement of resting energy expenditure is not possible because the energy cost of activity is not included in the balance equation. Nevertheless if one assumes an increment of between 10 and $40 \%$ for the daily activities of a hospitalised subject taking intermittent exercise, then the cumulative energy balance is between the limits of 300 to $500 \mathrm{MJ}$. The energy balance calculated from anthropometry (360 $\mathrm{MJ}$ ) is consistent with the above estimate.

During the course of intravenous feeding the resting energy expenditure rose progressively from 4.35 to $7.2 \mathrm{~kJ} / \mathrm{min}$. This largely reflects the demands of increased lean body mass together with a small increment for dietary induced thermogenesis. During the highest level of energy intake the dietary induced thermogenesis was estimated to be about $10 \%$ of the energy intake. In this patient there was no evidence of 'luxusconsumption', the mechanism which has been proposed to limit the increase in body fat when lean people are overfed. ${ }^{4}$
During the course of the study repeated measurements of respiratory quotient provide another observation of interest. As expected the respiratory quotient was high during the infusions of high calorie feeds, but remained persistently above 1.0 up to nine hours postfeed. This suggests continued lipogenesis from carbohydrate, with glycogen as the unusual substrate, during the post-feeding period.

These data provide information regarding nutritional repletion in a patient who showed no evidence of active inflammatory disease after the first week of intravenous feeding.

We wish to thank Dr J O Hunter for allowing us to study his patient.

\section{MRC Dunn Clinical Nutritional Centre, 100 Tennis Court Road, Cambridge CB2 1QL}

\section{References}

1 Durnin JVGA, Womersley J. Body fat assessed from total body weight and its estimation from skinfold thickness: measurements on 481 men and women aged from 16 to 72 years. Br J Nutr 1974; 32: 77-97.

2 Lukaski HC, Johnson PE, Bolonchuk WW, Lyknen GI. Assessment of fat free mass using bioelectrical impedance measurements of the human body. Am J Clin Nutr 1985; 41: 810-7.

3 Grant JP, Administration of Parenteral Nutrition Solutions. In: Handbook of total patenteral nutrition. Philadelphia: WB Saunders, 1980.

4 Neumann RO. Experimentelle Beiträge zur lehre von dem taglichen Nahrungsbedarf des Menschen unter besonderer Berucksichitigung der notwendigen Eiwesmange. Arch Hyg 1902; 45: 1-87. 